\title{
A combined human case of Dirofilaria ursi (1) CrossMark infection in dorsal subcutaneous tissue and Anisakis simplex sensu stricto (s.s.) infection in ventral subcutaneous tissue
}

\author{
Minoru Yamada ${ }^{*}$, Namiko Shishito ${ }^{2}$, Yoshihiro Nozawa ${ }^{2}$, Shigehiko Uni ${ }^{3}$, Keisuke Nishioka ${ }^{1}$ and Takaaki Nakaya ${ }^{1}$
}

\begin{abstract}
Background: Dirofilaria ursi is a filarial nematode that parasitizes the subcutaneous tissues of the American black bear (Ursus americanus) and Japanese black bear (Ursus thiabetanus japonicus). D. ursi that has parasitized black bears has the potential to subsequently infect humans. In addition, extra-gastrointestinal anisakiasis is less common in Japan.

Case presentation: We report a case of ventral subcutaneous anisakiasis and dorsal subcutaneous dirofilariasis that was acquired in Fukushima, in the northern part of Japan. The patient was an 83-year-old Japanese female, and subcutaneous parasitic granulomas were present on her left abdomen (near the navel) and left scapula. A pathological examination of the surgically dissected tissue sections from each region demonstrated eosinophilic granulomas containing different species of parasites. To enable the morphological and molecular identification of these parasites, DNA was extracted from paraffin-embedded sections using DEXPAT reagent, and the cytochrome oxidase 2 (COX2), internal transcribed spacer 1 (ITS1), 5.8S and ITS2 regions of the Anisakis larvae, and the 5S rRNA region of the male Dirofilaria were sequenced. The PCR products were examined and compared with DNA databases. Molecular analysis of the COX2 and $5 S$ rRNA sequences of each worm revealed that the nematode found in the ventral region belonged to Anisakis simplex sensu stricto (s.s.) and the male Dirofilaria found in the dorsal region was classified as D. ursi.
\end{abstract}

Conclusion: The present case showed a combined human case of D. ursi and A. simplex s.s. infections in subcutaneous tissues. The results of this study will contribute to the identification of unknown parasites in histological sections.

Keywords: Helminthic subcutaneous infections, Dirofilaria ursi, Anisakis simplex sensu stricto (s.s.), A combined human case

\section{Background}

Dirofilaria ursi is a filarial nematode that parasitizes the subcutaneous tissues of the American black bear (Ursus americanus) and Japanese black bear (Ursus thiabetanus japonicus) [1]. It is vectored by black flies in many parts of the USA and Japan. The Center for Diseases Control and Prevention in the USA has suggested that $D$. ursi has the potential to subsequently infect humans [2]. D. ursi was shown to parasitize the subscapular connective tissue and perirenal adipose tissue of a black bear in Tamba district,

\footnotetext{
* Correspondence: minori@koto.kpu-m.ac.jp

'Department of Infectious Diseases, Kyoto Prefectural University of Medicine, Kyoto, Japan

Full list of author information is available at the end of the article
}

Hyogo Prefecture, in the western part of Japan [3]. The morphology of $D$. ursi has been studied extensively and described in detail [4]. We also identified the same nematode female and male worms parasitizing the cervical subfascia of a black bear in Miyama district, near Tamba district, Kyoto Prefecture, Japan.

The present human case occurred in Shirakawa city, Fukushima Prefecture, in the northern part of Japan, in which $D$. ursi infection has not been detected in black bears even though black bears frequently appear around this area and school children carry bells to scare wandering bears.

The Center for Diseases Control and Prevention in the USA described the life cycle of Anisakis, a nematode 
that parasitizes the gastrointestinal mucosa of humans. The paratenic hosts of anisakiasis are marine fishes, with salmon now being the main infective source for humans in Japan [5]. Salmon is regularly consumed in Japan. We have the recent data that all anisakis species collected from salmons: The collected worms from Oncorhynchus keta, chum salmon (11 positive/11 examined); Oncorhynchus masou, masu salmon (2/2); Oncorhynchus gorbuscha, pink salmon (2/2); and Oncorhynchus nerka, Sockeye salmon (5/5) were Anisakis simplex sensu stricto (s.s.) larvae, comparing with those from mackerel (28 positive/53 examined). Although more than 2000 gastrointestinal cases occur every year [6, 7], extra-gastrointestinal anisakiasis is less common, with only approximately 60 cases being reported to date $[6,8]$. A case of Anisakis pegreffii, one of the siblings of $A$. simplex, was molecularly described from archival paraffin sections of Italian and Croatian patients $[9,10]$. We herein reported a combined case of $D$. ursi infection and granulomatous $A$. simplex s.s. infection based on tissue sections.

\section{Case presentation}

The patient was an 83-year-old Japanese female. She previously worked as a farmer and lived by herself in Shirakawa city, Fukushima Prefecture. Subcutaneous parasitic granulomas were present on the left abdomen (near the navel) and left scapula with itching when admitted to the hospital. A pathological examination of surgically dissected tissue sections from each region revealed eosinophilic granulomas containing different species of parasites. One month later, the patient was admitted to the hospital with fever, weight loss, diarrhea, and vomiting. She had systemic lymphadenopathy and hepatosplenomegaly. She was tentatively diagnosed with diffuse large B cell lymphoma based on bone marrow biopsy findings. She died due to the systemic metastasis of lymphoma (without any parasitic granulomas appearing on her skin) approximately 2 weeks after her admission.

In order to enable the morphological and molecular identification of these parasites, morphological check points were compared in the worms appeared in subcutaneous tissues in detail and reexamined genetically. For molecular identification, the total DNA was extracted from paraffin-embedded sections using DEXPAT reagent (Takara Japan) and QIAmp DNA Mini Kit (Qiagen $\mathrm{GmbH}$, Germany). The ITS region (internal transcribed spacer 1) (ITS1, 5.8S rRNA, and ITS2) and mitochondrial DNA region of COX2 of Anisakis were amplified by PCR using the extracted Anisakis larvae and sequenced [11]. Each of the primers used for PCR amplification of $A n i$ sakis DNA was 5'-TGAACCTGCGGAAGGATCA-3 (forward) and 5'-CGGGTAATCACGACTGAGCT-3' (reverse) for ITS1-5.8S rRNA-ITS2 region (700 bp) and 5' -TCAGGATTTTGGTTTGATGTTT-3' (forward) and 5'-ATTCTCCATAAAACCTATACAC-3' (reverse) for COX2 region $(682 \mathrm{bp})$. The mixture was denatured at $94{ }^{\circ} \mathrm{C}$ for $3 \mathrm{~min}$, followed by 40 cycles at $94{ }^{\circ} \mathrm{C}$ for $30 \mathrm{~s}$, $48^{\circ} \mathrm{C}$ for $40 \mathrm{~s}$, and $72{ }^{\circ} \mathrm{C}$ for $50 \mathrm{~s}$, with final extension at $72{ }^{\circ} \mathrm{C}$ for $7 \mathrm{~min}$ on a thermocycler (GeneAmp PCR System 9700; Applied Biosystems, Foster City, CA, USA) for ITS and COX2 products. Electrophoresis confirmed the 700-bp PCR product of ITS region and 682-bp PCR product of COX2 of Anisakis DNA amplification.

The 5S rDNA sequence of Dirofilaria species was amplified and analyzed by PCR using different four reverse primer sets with the same former primer set for the species identification of $D$. ursi. The selected primers used for PCR amplification of Dirofilaria species was forward (5' -TGGGCCTGGTTAGTACTTGG-3') and reverse (5'-GGGCCGTAACATTCAGTCAG-3') primers for $5 \mathrm{~S}$ rRNA. The mixture was denatured at $94^{\circ} \mathrm{C}$ for $3 \mathrm{~min}$, followed by 40 cycles at $94{ }^{\circ} \mathrm{C}$ for $30 \mathrm{~s}, 63^{\circ} \mathrm{C}$ for $40 \mathrm{~s}$, and $72{ }^{\circ} \mathrm{C}$ for $50 \mathrm{~s}$, with final extension at $72{ }^{\circ} \mathrm{C}$ for $7 \mathrm{~min}$ on a thermocycler for $5 \mathrm{~S}$ rRNA product (187 bp). Electrophoresis confirmed the 187-bp PCR product of Dirofilaria DNA amplification. The amplified polymerase chain reaction (PCR) products were examined and compared with DNA databases. A molecular analysis was conducted on the COX2 of Anisakis and 5S rRNA sequences of Dirofilaria. PCR products of a $5 \mathrm{~S}$ rRNA of $D$. ursi were directly sequenced and also cloned in a pGEM-T easy vector (Promega) containing the T7 and SP6 promoter sequences around multiple cloning sites according to the manufacturer's protocol. The plasmid-cloned 187-bp PCR product was purified using a GenEluteTM HP Plasmid Miniprep kit (Sigma-Aldrich). After purification, the plasmid was sequenced using T7 promoter $\left(5^{\prime}\right.$-TAATAC GACTCACTATAGG-3') and SP6 promoter (5'-ATTT AGGTGACACTATAGAA-3') primers and a BigDye Terminator v3.1 cycle Sequencing kit (Applied Biosystems) following the manufacturer's protocols. Sequences were obtained using an ABI Genetic Analyzer (Applied Biosystems). As a result, we obtained full-length sequences of the cloned PCR products. Sequences were assembled and aligned using Genetyx version 11 (Genetyx Corporation) [12]. Sequence regions were identified using BLAST searches and comparisons with the sequences of $D$. ursi and Dirofilaria immitis, which had been deposited in the GenBank database (GenBank accession nos. GQ241944, GQ241942, GQ241943, GQ241945, FJ874773.1, and EU360964). The morphological definitions of the two parasitic granulomas were analyzed in $H \& E$ sections. The ventral subcutaneous granuloma was $46 \times 20 \times 25 \mathrm{~mm}$ in size, while the dorsal subcutaneous granuloma was $28 \times 15 \times 15 \mathrm{~mm}$. 
Cross sections of the larva of the nematode Anisakis were detected in ventral subcutaneous tissue (Fig. 1a, b). These sections showed Anisakis larva based on the morphological appearance of the structures of the cuticle, muscle, lateral chord, rennet cell, and transverse striations. PCR was conducted for the COX2 and ITS1-5.8S rRNA-ITS2 regions of Anisakis larva. The ITS sequences showed close similarity in the siblings such as A. simplex s.s. and $A$. pegreffii. So, COX2 gene was chosen as the target sequence in the reason why COX2 region of mtDNA is well known to be less than ITS1-5.8S rRNAITS2 region of nuclear DNA in the base substitution. The regions of COX2 were identified using BLAST searches and comparisons with the sequences of $A$. simplex s.s. and $A$. pegreffii, which had been deposited in the GenBank database (GenBank accession nos. AB517562, HQ702744, and DQ116426). Multiple sequence alignment was carried out using the Genetyx ver 11 software. A genetic analysis of the DNA sequence from the nucleotide COX2 sequences (532 bp, partial sequence) of this Anisakis species was similar to that of $A$. simplex s.s. but different from that of $A$. pegreffii with $98.5 \%$ identity to $A$. simplex s.s. and $92.2 \%$ identity to $A$. pegreffii at 8 positions. The phylogenetic tree based on COX2 sequences analysed by Genetyx ver 11 software revealed that this specimen belongs to $A$. simplex s.s. (Fig. 2).

Cross sections of the nematode Dirofilaria species were detected in dorsal subcutaneous tissue (Fig. 3). The present case was diagnosed as dirofilariasis due to male adults because of the presence of seminal vesicles in the center of the section. Dirofilaria species were 200$360 \mu \mathrm{m}$ in diameter (body width) (Table 1). There were 65-82 longitudinal ridges (Table 1). The distance between longitudinal ridges was 5-12.5 $\mu \mathrm{m}$ (Table 1). PCR amplification with primers directed to the mitochondrial 16S rRNA region of D. immitis [13] and COX1 region of Dirofilaria repens [14] and COX1 region of Onchocerca dewittei japonica [15] was conducted. PCR products of the D. immitis $16 \mathrm{~S} \mathrm{rRNA}, D$. repens COX1, and $O$. dewittei japonica COX1 regions were all negative. The diameter, cuticle thickness, number of longitudinal ridges, and distance between longitudinal ridges on the surface of the present Dirofilaria species in human dorsal lesions are summarized in Table 1. These results indicated that the present Dirofilaria species was very similar to D. ursi. PCR amplification with primers directed to the mitochondrial $5 \mathrm{~S}$ rRNA of $D$. ursi was conducted. The PCR product of Dirofilaria species was amplified using four different reverse primers, with the same primers being used for the species identification of D. ursi. A genetic analysis of DNA sequences from the nucleotide $5 \mathrm{~S}$ rRNA region (95 bp, partial sequence) of this Dirofilaria species revealed $97.4 \%$ identity to $D$. ursi and $89.3 \%$ to $D$. immitis. Moreover, sequences obtained by the TA cloning of PCR products (187 bp, partial) from this Dirofilaria species showed $98 \%$ identity to $D$. ursi and $84 \%$ identity to $D$. immitis. A phylogenetic relationship according to the $5 \mathrm{~S}$ rRNA gene $(90 \mathrm{bp}$, partial sequence) was conducted, and the present Dirofilaria worm was very similar to $D$. ursi (GenBank accession nos. GQ241944, GQ241942, GQ241943, GQ241945, FJ874773.1, and EU360964). The phylogenetic tree of this $D$. ursi containing worms collected from Japanese black bears in Gifu (the middle part of Japan) based on 5S rRNA sequences is shown in Fig. 4.

\section{Discussion and conclusions}

We herein present a combined human case of $D$. ursi infection in dorsal subcutaneous tissue and a granulomatous $A$. simplex s.s. infection in ventral subcutaneous tissue. These subcutaneous parasitic lesions were operated and removed but had not been recognized these subcutaneous nodules until operation because of living by herself and nobody detected. Anisakiasis is one of the most important zoonoses reported worldwide every year, particularly in countries in which eating raw fish is a custom. More than 2000 cases of anisakiasis are reported every year in Japan, and this number has

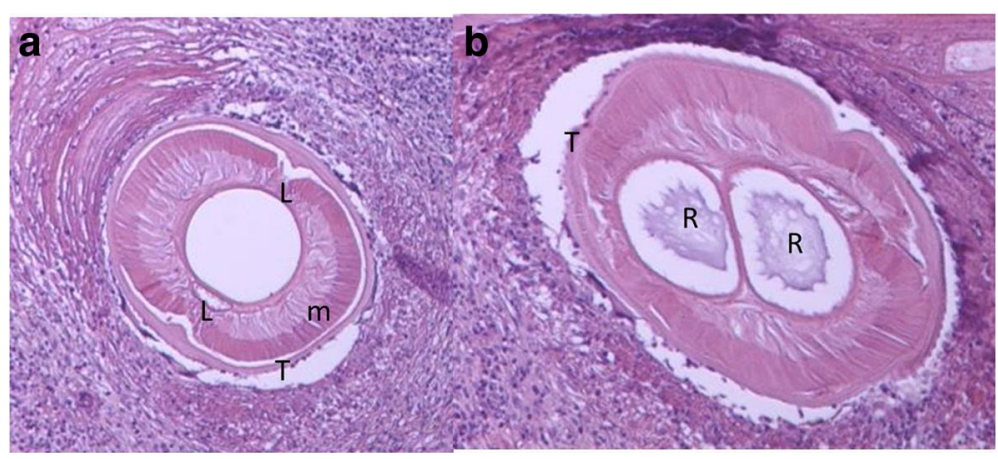

Fig. 1 a, b Paraffin section of Anisakis larva in a ventral subcutaneous lesion. $m$ muscle, $L$ lateral chord, R rennet cell, T transverse striation 


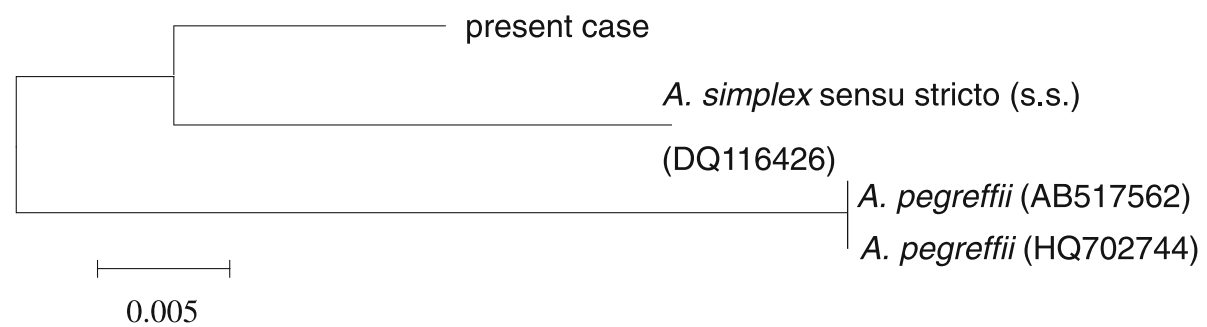

Fig. 2 Phylogenetic analysis of Anisakis species based on COX2 sequences (532 bp). Nucleotide sequences were aligned and phylogenetic tree analysis was conducted using the Genetyx ver 11 software

recently increased, possibly due to the custom of eating various raw or undercooked fishes as sashimi or sushi. Additionally, extra-gastrointestinal anisakiasis is less common and caused by a larval Anisakis nematode which escaped the gastrointestinal wall and makes a lesion at the abdominal wall and cavity, abdominal omentum, mesentery, and subcutaneous tissues, with only approximately 60 cases being reported to date in Japan. The pathogenic potential of two sibling nematodes, A. simplex s.s. and A. pegreffii derived from living larvae or larvae in tissue sections, was demonstrated based on in vitro penetration ability, acid tolerance, and in vivo experimental infection studies [16, 17]. This case was finally found to be Anisakis species similar to A. simplex s.s. using a DNA analysis of tissue sections. It is important to clearly differentiate between $D$. ursi and $D$. immitis because of their similar morphologies. The body width of the midbody of $D$. ursi was $380-520 \mu \mathrm{m}$, and the distance between longitudinal ridges was 9-14 $\mu \mathrm{m}$. Furthermore, Dirofilaria has to be morphologically differentiated from filarial Onchocerca species in cross

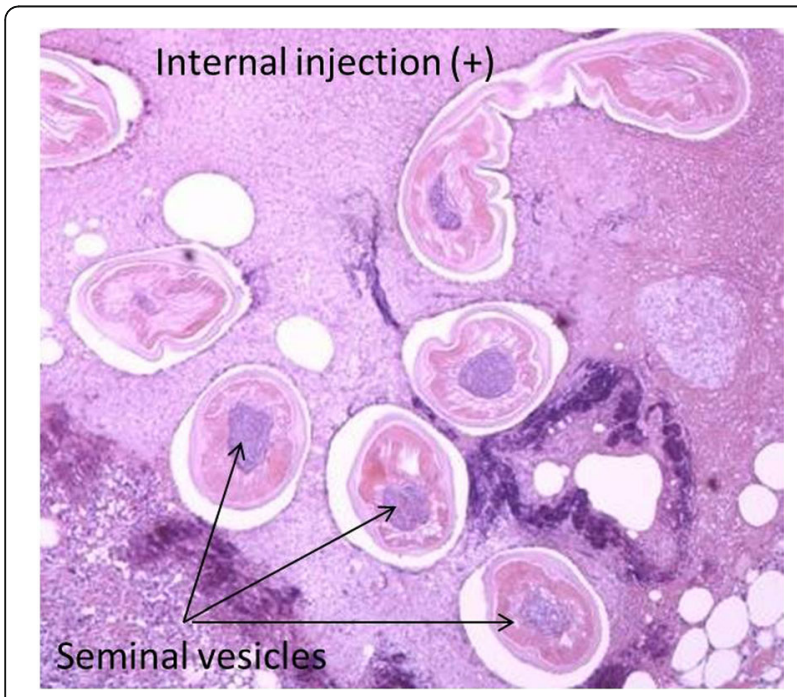

Fig. 3 Paraffin section of Dirofilaria species in a dorsal subcutaneous lesion sections of subcutaneous tissues because both are causative agents in subcutaneous nodules and vectored by black flies, while their final hosts are different. The body width of $O$. dewittei japonica collected from wild boars was previously reported to be $85-135 \mu \mathrm{m}$ [1821]. The cuticle of Dirofilaria species (final host: wild boar) has internal projections, whereas $O$. dewittei japonica does not. The thickness of the cuticle of $D$. ursi was very thin, whereas that of $O$. dewittei japonica was thick and composed of 4-5 layers. The number of longitudinal ridges was lower in $D$. ursi than in O. dewittei japonica. The longitudinal ridges of $O$. dewittei japonica were shorter and more prominent than those of $D$. ursi. The number of longitudinal ridges in $O$. dewittei japonica was $138-152$, whereas that in $D$. ursi was 62. In conclusion, a molecular analysis of the COX2 and $5 \mathrm{~S}$ rRNA sequences of each worm revealed that the Anisakis larva found in the ventral region belonged to A. simplex s.s. and the male Dirofilaria found in the dorsal region was diagnosed as $D$. ursi.

The present case showed a combined human case of $D$. ursi and A. simplex s.s. infections. The results of this study will contribute to the identification of unknown

Table 1 Summary of the width and number of longitudinal ridges on the surface of Dirofilaria species in a dorsal lesion

\begin{tabular}{lllll}
\hline Section & $\begin{array}{l}\text { Diameter } \\
(\mu \mathrm{m})\end{array}$ & $\begin{array}{l}\text { Thickness } \\
\text { of cuticle }(\mu \mathrm{m})\end{array}$ & \multicolumn{2}{c}{ Longitudinal cuticular ridges } \\
\cline { 5 - 5 } & & Number & Distance $(\mu \mathrm{m})$ \\
\hline 1 & $200-270$ & 15 & 77 & 5 \\
2 & $250-310$ & 12.5 & 70 & 10 \\
3 & $240-280$ & 15 & 69 & 10 \\
4 & $250-320$ & 10 & 72 & 10 \\
5 & $250-310$ & 12.5 & 72 & 12.5 \\
6 & $230-360$ & 15 & 71 & 7.5 \\
7 & $250-315$ & 17.5 & 82 & 10 \\
8 & $200-320$ & 12.5 & 65 & 10 \\
9 & $270-320$ & 7.5 & 71 & 7.5 \\
10 & $220-310$ & 12.5 & 72 & 7.5 \\
\hline
\end{tabular}




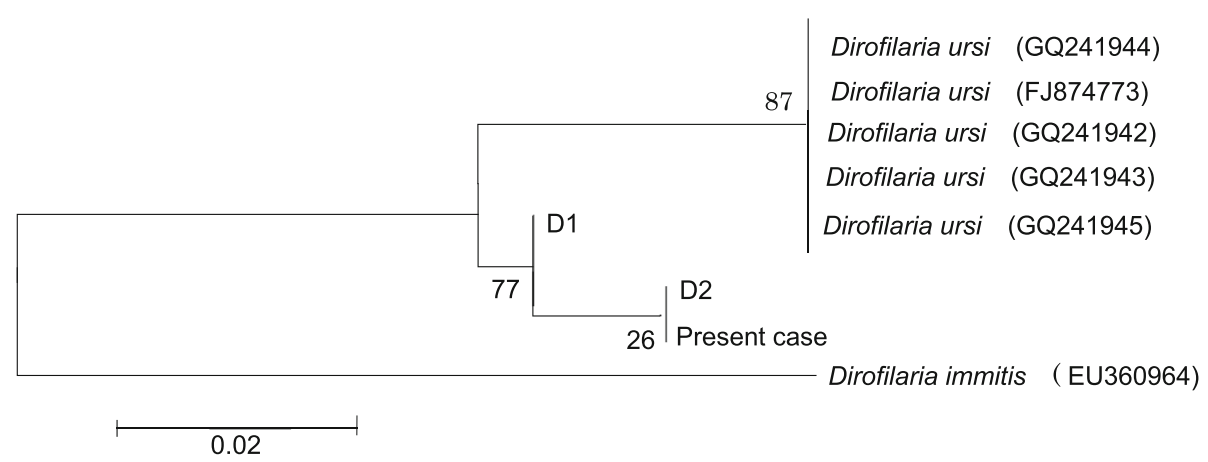

Fig. 4 Phylogenetic analysis of Dirofilaria species based on 5S rRNA sequences (90 bp). Nucleotide sequences were aligned using the Genetyx ver 11 and CLC Sequence Viewer 6 software. Phylogenetic analyses were conducted using the Mega 6 software. Genetic relationships were inferred by the neighbor-joining (NJ) method. D1 and D2 means Dirofilaria ursi worms collected from Japanese bears in Gifu Prefecture in the middle part of Japan

parasites appeared in histological sections. Additionally, a recent molecular analysis showed that this $D$. ursi was very similar to one of the $D$. ursi collected from a Japanese black bear (captured in Gifu Prefecture in the middle part of Japan). The difference between Japanese D. ursi and American D. ursi was 3-4\%.

\section{Acknowledgements}

We sincerely thank Mr. Masatsugu Kakumoto and Takumi Wadayama who are medical students and helped to publish the case report.

\section{Funding}

No funding received.

\section{Availability of data and materials}

All the data and information supporting our conclusions are included in the manuscript.

\section{Authors' contributions}

MY, SU, KN, and TN contributed to the diagnostic parasitology of the parasites appeared in the tissue sections and wrote the manuscripts. NS and YN contributed to the diagnostic pathology of the human tissue sections in Shirakawa Kosei General Hospital. All authors read and approved the final manuscript.

\section{Ethics approval and consent to participate}

This is not a research project involving people or animals, only a case report. Therefore, the requirement in our local setting is to get consent for publication.

\section{Consent for publication}

Written informed consent was obtained from the patient for the publication of this case report and any accompanying images.

\section{Competing interests}

The authors declare that they have no competing interests.

\section{Publisher's Note}

Springer Nature remains neutral with regard to jurisdictional claims in published maps and institutional affiliations.

\section{Author details}

'Department of Infectious Diseases, Kyoto Prefectural University of Medicine, Kyoto, Japan. ${ }^{2}$ Department of Pathology, Shirakawa Kosei General Hospital, Fukushima, Japan. ${ }^{3}$ Institute of Biological Sciences, Faculty of Science, University of Malaya, Kuala Lumpur, Malaysia.
Received: 2 June 2017 Accepted: 28 August 2017

Published online: 01 November 2017

\section{References}

1. Michalski ML, Bain O, Fischer K, Fischer PU, Kumar S, Foster JM. Identification and phylogenetic analysis of Dirofilaria ursi (Nematoda: Filarioidea) from Wisconsin black bears (Ursus americanus) and its Wolbachia endosymbiont. J Parasitol. 2010;96:412-9.

2. Beaver PC, Wolfson JS, Waldron MA, Swartz MN, Evans GW, Adler J. Dirofilaria ursi-like parasites acquired by humans in the northern United States and Canada: report of two cases and brief review. Am J Trop Med Hyg. 1987;37:357-62.

3. Uni S, Kimata I, Takada S. Cross-section of Dirofilaria ursi in comparison with D. immitis. Jpn J Parasit. 1980;29:489-97.

4. Uni S. Filarial parasites from the black bear of Japan. Ann Parasitol Hum Comp. 1983:58:71-84.

5. Quiazon KMA, Yoshinaga T, Ogawa K, Yukami R. Morphological differences between larvae and in vitro-cultured adults of Anisakis simplex (sensu stricto) and Anisakis pegreffii (Nematoda: Anisakidae). Parasitol Int. 2008:57:483-9.

6. Kagei N, Orikasa H, Hori E, Sannomiya A, Yasumura Y. A case of hepatic anisakiasis with a literal survey for extra-gastrointestinal anisakiasis. Jap J Parasit. 1995:44:346-51.

7. Ishikura H. Anisakiasis(2). Clinical pathology and epidemiology. In: Progress of medical parasitology in Japan. Vol. 8. Tokyo: Meguro Parasitological Museum; 2003. p. 451-3.

8. Ishikura H, Sato N, Wada Y, Kikuchi K, Ooiwa T, Matsui T, Yamamoto Y, Nakata H, Toyonaga J, Ookita H, Tsukioka T, Fukumoto S, Kurokawa K. Diagnostic methods of intestinal anisakiasis. Nihon-Ishikai-Zatsushi. 1990;104:1132-40.

9. Mattiucci S, Paoletti M, Borrini F, Palumbo M, Palmieri RM, Gomes V, Casati A, Nascetti G. First molecular identification of the zoonotic parasite Anisakis pegreffii (Nematoda: Anisakidae) in a paraffin-embedded granuloma taken from a case of human intestinal anisakiasis in Italy. BMC Infect Dis. 2011;11: 82. http://www.biomedcentral.com/1471-2334/11/82

10. Mladineo I, Propovic M, Drmic-Hofman I, Poljak V. A case report of Anisakis pegreffi (nematode, Anisakidae) identified from archival paraffin sections of a Croatian patient. BMC Infec Dis. 2016;16:42. https://doi.org/ 10.1186/s12879-016-1401-x.

11. Arizono N, Yamada M, Tegoshi T, Yoshikawa M. Anisakis simplex sensu stricto and Anisakis pegreffii: biological characteristics and pathogenetic potential in human anisakiasis. Foodborne Pathog Dis. 2012;9:517-21.

12. Altschul SF, Gish W, Miller W, Myers EW, Lipman DJ. Basic local alignment search tool. J Mol Biol. 1990;215:403-10.

13. Hyun-Wook O, Hyung-Kyou J, Myung-Jo Y, Hayasaki M, Kun-Ho S. Ectopic migration of an adult heartworm in a dog with dirofilariasis. Korean J Parasit. 2008:46:171-3.

14. Baptista-Fernandes T, Rodrigues M, Domingues D, Monteiro L, Paixao P, Pereira P, Tavares R, Rodrigues P, Mauricio I, Belo S, Toscano C. Dirofilariasis by Dirofilaria repens: an imported case and a brief review. Parasitol Int. 2015;64:261-3. 
15. Uni S, Boda T, Daisaku K, Ikura Y, Maruyama H, Hasegawa H, Fukuda M, Takaoka H, Bain O. Zoonotic filariasis caused by Onchocerca dewittei japonica in a resident of Hiroshima Prefecture, Honshu. Japan Parasitol Int. 2010;59: 477-80.

16. Jeon C-H, Kim J-H. Pathogenic potential of two sibling species, Anisakis simplex (s.s.) and Anisakis pegreffii (Nematoda: Anisakidae): in vitro and in vivo studies. BioMed Res Int. 2015;Article ID 983656:9. http://dx.doi.org/10. 1155/2015/983656

17. Nogami Y, Fujii-Nishimura K, Banno K, Suzuki A, Susumu N, Hibi T, Murakami K, Yamada T, Sugiyama H, Morishima Y, Aoki D. Anisakiasis mimics cancer recurrence: two cases of extragastrointestinal anisakiasis suspected to be recurrence of gynecological cancer on PET-CT and molecular biological investigation. BMC Med Imag. 2016;16:31. https:// doi.org/10.1186/s1 2880-016-0134-z

18. Fukuda M, Otsuka Y, Uni S, Bain O, Takaoka H. Genetic evidence for the presence of two species of Onchocerca from the wild boar in Japan. Parasite. 2010;17:39-45.

19. Fukuda M, Otsuka Y, Uni S, Boda T, Daisaku H, Hasegawa H, Takaoka H, Bain O. Zoonotic onchocerchiasis in Hiroshima, Japan and molecular analysis of a paraffin section of the agent for a reliable identification. Parasite. 2011;18:185-8.

20. Uni S, Fukuda M, Otsuka Y, Hiramatsu N, Yokobayashi K, Takahashi H, Murata S, Kusatake K, Morita E, Maruyama H, Hasegawa H, Shiwaku K, Ramli R, Azirun MS, Takaoka H. New zoonotic cases of Onchocerca dewittei japonica (Nematoda: Onchocercidae) in Honshu. Japan Parasites Vectors. 2015;8:59. http://dx.doi.org/10.1186/s13071-015-655-2

21. Fukuda M, Uni S, Otsuka Y, Eshita Y, Nakatani J, Ihara K, Yoshikawa Y, Goto M, Fujiwara S, Ramli R, Azirun MS, Takaoka H. A new case of zoonotic onchocercosis in northern Kyushu, Japan. Parasitol Int. 2015;64:519-21.

\section{Submit your next manuscript to BioMed Central and we will help you at every step:}

- We accept pre-submission inquiries

- Our selector tool helps you to find the most relevant journal

- We provide round the clock customer support

- Convenient online submission

- Thorough peer review

- Inclusion in PubMed and all major indexing services

- Maximum visibility for your research

Submit your manuscript at www.biomedcentral.com/submit
Biomed Central 